ARTICLE

Received 23 Nov 2015 | Accepted 28 Apr 2016 | Published 3 Jun $2016 \quad$ DOl: 10.1038/ncomms11774

\title{
Freestanding three-dimensional core-shell nanoarrays for lithium-ion battery anodes
}

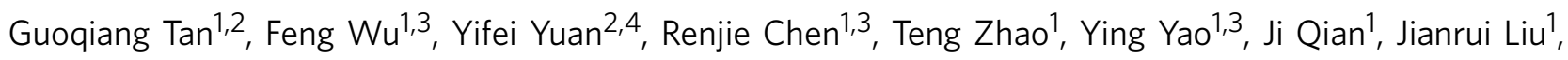
Yusheng Ye ${ }^{1}$, Reza Shahbazian-Yassar ${ }^{4}$, Jun $\mathrm{Lu}^{2} \&$ Khalil Amine ${ }^{2}$

Structural degradation and low conductivity of transition-metal oxides lead to severe capacity fading in lithium-ion batteries. Recent efforts to solve this issue have mainly focused on using nanocomposites or hybrids by integrating nanosized metal oxides with conducting additives. Here we design specific hierarchical structures and demonstrate their use in flexible, large-area anode assemblies. Fabrication of these anodes is achieved via oxidative growth of copper oxide nanowires onto copper substrates followed by radio-frequency sputtering of carbon-nitride films, forming freestanding three-dimensional arrays with core-shell nano-architecture. Cable-like copper oxide/carbon-nitride core-shell nanostructures accommodate the volume change during lithiation-delithiation processes, the three-dimensional arrays provide abundant electroactive zones and electron/ion transport paths, and the monolithic sandwich-type configuration without additional binders or conductive agents improves energy/power densities of the whole electrode.

\footnotetext{
${ }^{1}$ School of Materials Science and Engineering, Beijing Institute of Technology, Beijing Key Laboratory of Environmental Science and Engineering, Beijing 100081, China. ${ }^{2}$ Chemical Sciences and Engineering Division, Argonne National Laboratory, 9700S. Cass Avenue, Lemont, Illinois 60439, USA. ${ }^{3}$ Collaborative Innovation Center of Electric Vehicles in Beijing, Beijing 100081, China. ${ }^{4}$ Department of Mechanical and Industrial Engineering, University of Illinois at Chicago, Chicago, Illinois 60607, USA. Correspondence and requests for materials should be addressed to F.W. (email: wufeng863@vip.sina.com) or to R.C. (email: chenrj@bit.edu.cn) or to J.L. (email: junlu@anl.gov).
} 
S tringent requirements for reliable, fast and highly efficient energy technologies are ever increasing because of the growing electronics market and electric vehicle industry. Currently, lithium-ion batteries dominate as power sources for portable electronics and are regarded as the most promising power sources for electric vehicles and grid applications. However, these widespread and long-term applications still require better batteries in terms of performance, safety and cost, which can be achieved by better utilization of electrode materials and/or an optimized design of battery configurations ${ }^{1-4}$.

Even though widely used, current commercial lithium-ion batteries containing a graphite anode have limited specific capacity and energy density in both portable and transportation applications ${ }^{5}$. Thus, new, low cost, safe anode materials with higher cycling capacity and power capability are urgently needed. In past decades, considerable efforts have been devoted to searching for superior anode materials, such as lithiated carbons, Si/Sn-based materials, Ti-based oxides and other metal oxides/sulfides/nitrides/fluorides/phosphides ${ }^{6-15}$. The $3 \mathrm{~d}$ transition-metal oxides $\left(M_{x} \mathrm{O}_{y}, M=\mathrm{Co}, \mathrm{Ni}, \mathrm{Fe}, \mathrm{Mn}, \mathrm{Cu}\right.$ and so on) have been proposed as promising anodes because they are capable of incorporating more than one $\mathrm{Li}$ per $3 \mathrm{~d}$ metal, giving significantly higher electrochemical capacities than those of conventional graphite anodes. The mechanism of Li reactivity of metal oxides differs from the classic Li-intercalation or Li-alloying processes ${ }^{16}$. The metal oxides are reduced to metal nanoparticles through a conversion reaction that involves the formation of $\mathrm{Li}_{2} \mathrm{O}$ :

$$
M_{x} \mathrm{O}_{y}+2 y \mathrm{Li}^{+}+2 y \mathrm{e} \leftrightarrow y \mathrm{Li}_{2} \mathrm{O}+x M
$$

Similar to the Li-alloying process, the conversion reaction leads to volume variation on electrochemical cycling. Therefore, pure metal oxide electrodes typically suffer from poor cyclability and poor power capability. To solve these issues, researchers have tried various strategies such as reducing particle size or using nanocomposites ${ }^{17,18}$. Reducing particle size is considered as an effective approach to reduce volume variation. Indeed, many nanostructures based on $3 \mathrm{~d}$ metal oxides, such as nanospheres, nanowires, nanorods, nanotubes, nanoplates, and hollow structures, have been summarized in a wealth of published articles $^{10,19-22}$. Using nanocomposites or hybrids by integrating metal oxides with conducting additives, such as graphitized carbons, carbon nanotubes, graphenes, conductive polymers and so on, have also been reported to improve the utilization of the active materials ${ }^{23-26}$. However, these traditional strategies appear far from practical applications due to limited cycling performance and/or complex fabrication process.

Among metal oxides, copper oxide $(\mathrm{CuO})$ has received attention owing to its advantages of high theoretical capacity $\left(670 \mathrm{mAhg}^{-1}\right)$, low cost, facile synthesis and environmental benignity ${ }^{26-29}$. Good cycling stability and high-rate performance are two critical factors in the development of metal oxide anodes. Herein, we induce a monolithic synthetic technique $e^{30,31}$, directly growing active materials onto metallic current collectors, to maintain high conductivity while avoiding the use of binders and conductive agents. Here, we rationally design a freestanding, three-dimensional (3D) sandwich-type composite electrode based on $\mathrm{CuO} /$ carbon-nitride $\left(\mathrm{CN}_{x}\right)$ core-shell nanoarchitecture. The electrode is prepared via thermal oxidization combined with radio-frequency magnetron sputtering. The typical synthesis route and deposition mechanism are illustrated in Fig. 1. Nanowire arrays of $\mathrm{CuO}$ are obtained through the oxidation of copper substrates (foil, grid and net), followed by deposition of ultrathin $\mathrm{CN}_{x}$ films through radio-frequency sputtering of a graphite target in a high-purity $\mathrm{N}_{2}$ gas, forming $3 \mathrm{D} \mathrm{CuO} / \mathrm{CN}_{x}$ core-shell nano-architectures. $\mathrm{CN}_{x}$ films are deposited onto both sides of the $\mathrm{CuO}$ nanosubstrate, forming a sandwich-type $\mathrm{CN}_{x} / \mathrm{CuO} / \mathrm{CN}_{x}$ composite. In this electrode, $\mathrm{CuO} / \mathrm{CN}_{x}$ core-shell nanocables serve as active materials; the $\mathrm{CN}_{x}$ coating provides good electron conduction and flexibility, as well as mechanical strength; and the $3 \mathrm{D}$ arrays have large surface areas, good permeability and abundant active sites. Furthermore, the $3 \mathrm{D}$ nanocomposites can be reduced into $\mathrm{Cu} / \mathrm{CN}_{x}$ core-shell nanocable arrays. These different $3 \mathrm{D}$ nanosubstrates $\left(\mathrm{CuO}, \mathrm{CuO} / \mathrm{CN}_{x}\right.$ and $\mathrm{Cu} / \mathrm{CN}_{x}$ ) are fabricated as electrodes and show stable cycling in coin-type cells for over 200 cycles. Hereafter, we refer to these specific composites with the acronyms $\mathrm{CNE}(\mathrm{CuO}$ nanowire electrode), $\mathrm{CCNE}\left(\mathrm{CuO} / \mathrm{CN}_{x}\right.$ nanocable electrode) and $\mathrm{CNNE}$ $\left(\mathrm{Cu} / \mathrm{CN}_{x}\right.$ nanocable electrode).

\section{Results}

Physical characteristics. The 3D nanoscale morphologies of $\mathrm{CNE}$, CCNE and CNNE grown on copper foil are observed by s.e.m. and transmission electron microscopy (TEM). In Fig. 2a-e, it is obvious that a high density of uniform $\mathrm{CuO}$ nanowires, with diameters in the range of $50-100 \mathrm{~nm}$ and lengths of $10-20 \mathrm{um}$, grows vertically onto the substrate. Similarly, in Fig. 2a,b dense array of uniform $\mathrm{CuO} / \mathrm{CN}_{x}$ nanocables is observed on the substrate. The thickness of the $\mathrm{CN}_{x}$ film after $40 \mathrm{~min}$ sputtering is $\sim 140 \mathrm{~nm}$, with a deposition rate of $3.5 \mathrm{~nm} \mathrm{~min}^{-1}$, as shown in Fig. 2f. After the reduction, in Fig. 2c, the entire surface of the substrate is still covered by a high density of $\mathrm{Cu} / \mathrm{CN}_{x}$ nanocables, which appear to be thinner and more curved than the $\mathrm{CuO} / \mathrm{CN}_{x}$ nanocables. The shape change is mainly caused by the volume decrease that occurred during the reduction of wire-like $\mathrm{CuO}$ cores into copper nanoparticles, forming new hollow $\mathrm{Cu} / \mathrm{CN}_{x}$ nanocables, as shown in Fig. $2 \mathrm{~g}$. The entire process of oxidation, deposition and reduction of these nanosubstrates is illustrated in Fig. 2d-h.

The morphologies of CNEs (Supplementary Fig. 1) and CCNEs (Fig. 3) prepared using different copper substrates are also observed by s.e.m. Figure $3 \mathrm{a}-\mathrm{c}$ are the optical photos of CCNE films with diameters of $1.0 \mathrm{~cm}$ based on foil, net and grid substrates, respectively. The surfaces of the copper substrates are tarnished after heat treatment in $\mathrm{O}_{2}$ at $600{ }^{\circ} \mathrm{C}$ followed by graphite deposition in $\mathrm{N}_{2}$ for $40 \mathrm{~min}$. Figure $3 \mathrm{~d}-\mathrm{f}$ show the corresponding s.e.m. images, which display the $3 \mathrm{D}$ nano-architectures of high-density wire-like nanostructures over the entire surfaces of these substrates. Among these substrates, the nanostructures grown on the inner edges of the nets and ridges of the grids appear to be much denser and longer than those grown on the surface of the foils. Figure $3 g-i$ exhibit high-magnification s.e.m. images, which confirm a uniform diameter of $300-400 \mathrm{~nm}$ for these wire-like nanostructures. Figure $3 \mathrm{j}$ illustrates the $3 \mathrm{D}$ nano-architectural models of these CCNEs.

The core-shell nanostructures in CCNEs are investigated by TEM. It can be observed from the s.e.m. image (Fig. 4a) that the nanostructure array exhibits clear core-shell structures. Therefore, the wire-like nanostructure is considered to be a nanocable. In Fig. 4b-g, TEM images reveal that the nanocables have inner cores with diameters of $50-100 \mathrm{~nm}$, and outer shells with diameters of $15-140 \mathrm{~nm}$. In general, the diameter of the $\mathrm{CuO}$ cores is determined by the oxidation temperature and time, and the thickness of the $\mathrm{CN}_{x}$ shells is mainly controlled by adjusting the deposition time. The element distribution in the nanocables is analysed by energy dispersive X-ray (EDX) spectroscopy. In Fig. 4f, the EDX elemental mapping of the nanocable (Fig. 4e) shows an intense signal for $\mathrm{Cu}$ and $\mathrm{O}$ in the middle and a uniform distribution of $\mathrm{C}$ and $\mathrm{N}$ across the shell, suggesting a uniform coverage of the $\mathrm{CN}_{x}$ film over the $\mathrm{CuO}$ core. 

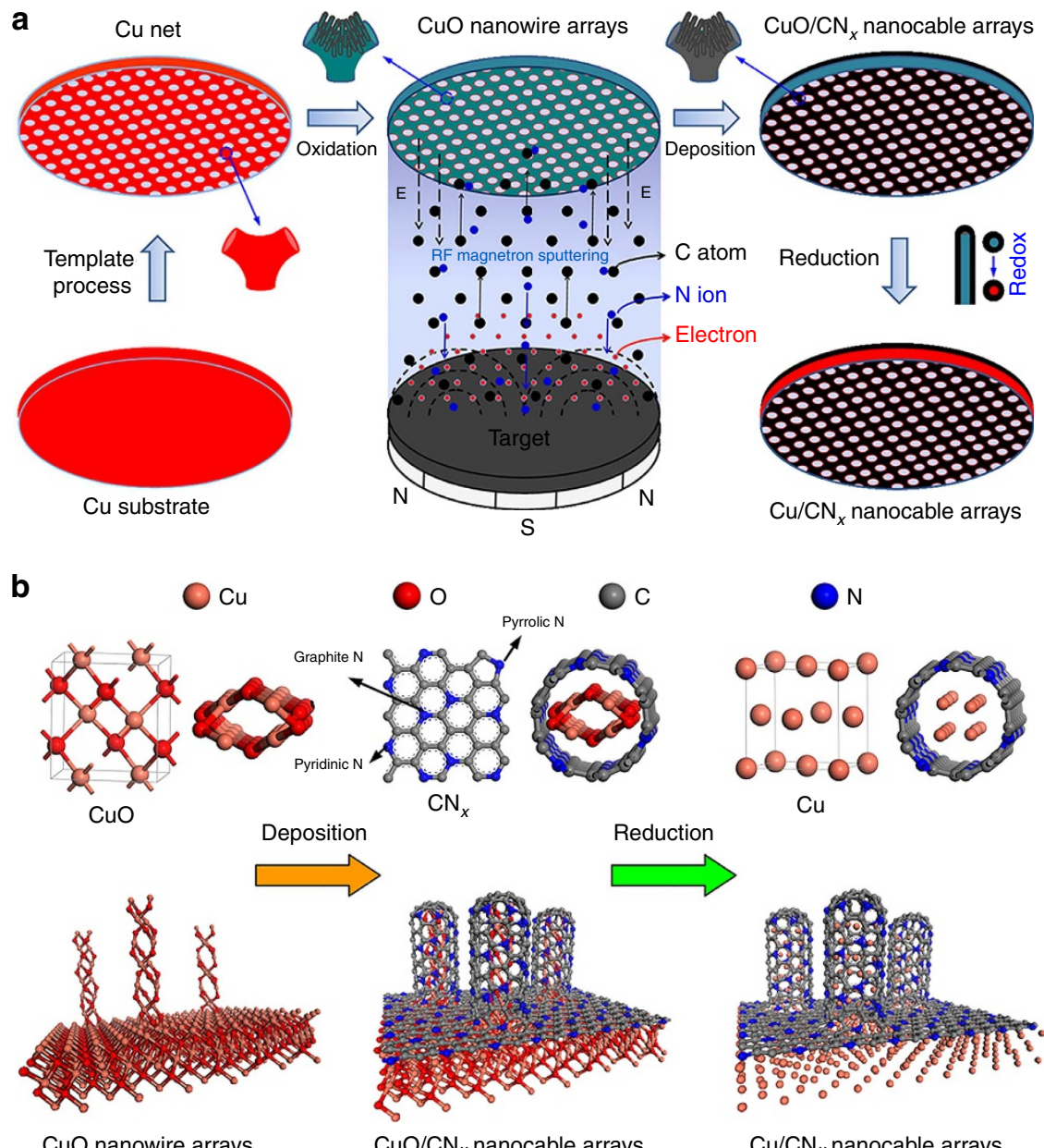

Figure 1 | Schematic of 3D arrays with the core-shell nano-architectural design. (a) The typical two-step electrode design consisting of the oxide growth of $\mathrm{CuO}$ nanowires onto a copper net substrate followed by radio-frequency magnetrson sputtering of $\mathrm{CN}_{x}$ films, forming a binder-free 3D array with core-shell nano-architecture. (b) Theoretical structural modelling showing the micro-mechanism of CNE, CCNE and CNNE formation.

a

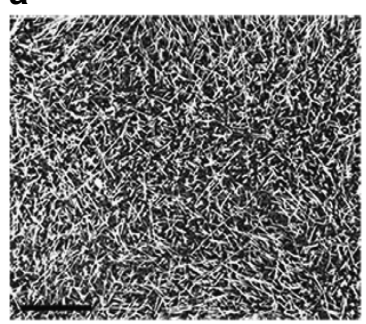

e

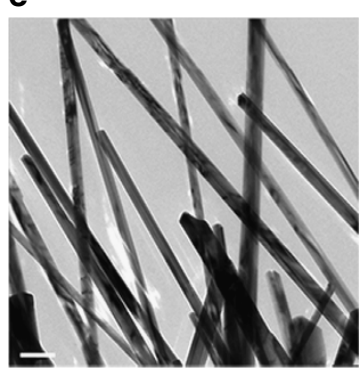

b

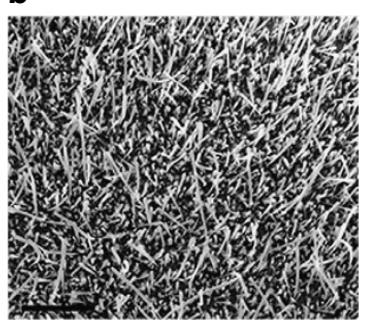

f

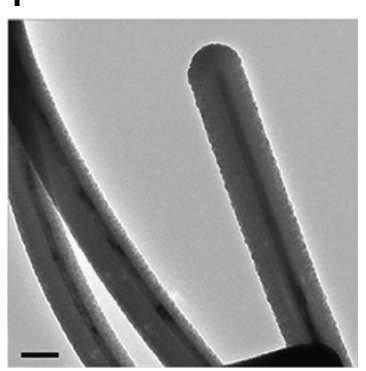

C

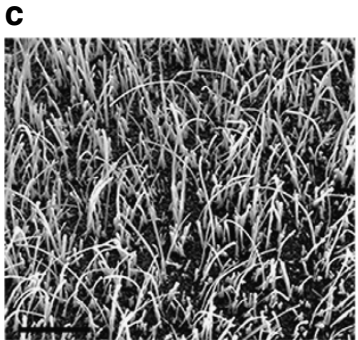

g

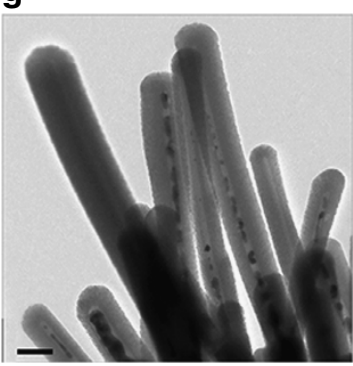

d

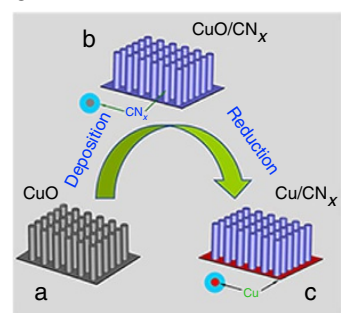

$\mathbf{h}$

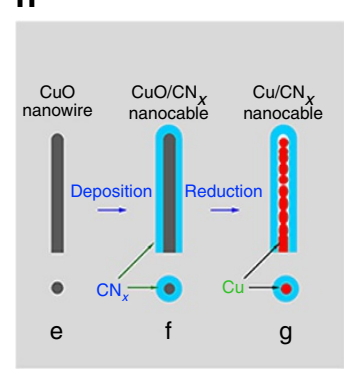

Figure 2 | Structure and morphology of nanocomposite electrodes. s.e.m. and TEM micrographs of the CNE (a,e), CCNE (b,f) and CNNE (c,g) based on the copper foils. (d,h) Schematic of the oxidation, deposition and reduction processes of the nanosubstrates. Scale bars in a-c, $20 \mu \mathrm{m}$; scale bars in $\mathbf{e}-\mathbf{g}, 200 \mathrm{~nm}$. 
a
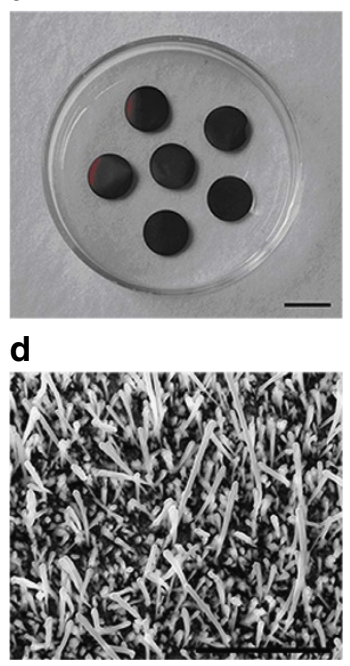

g

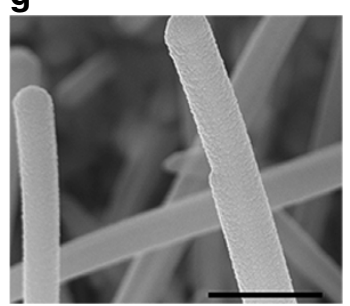

b

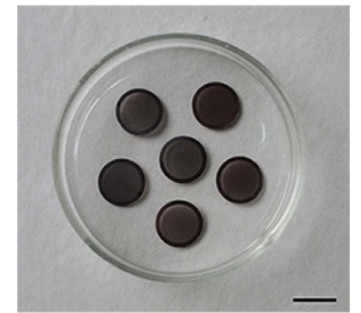

e

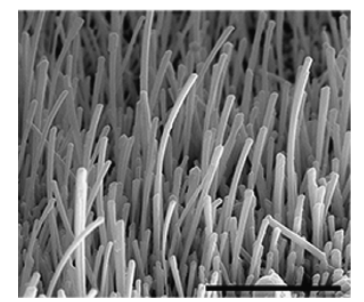

h

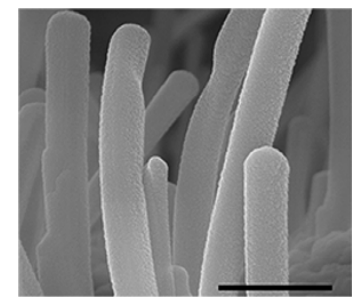

c

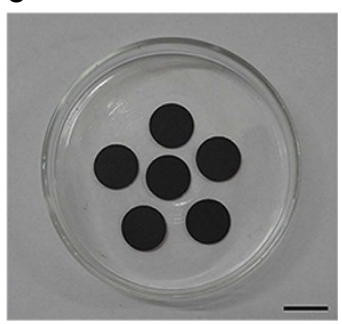

f

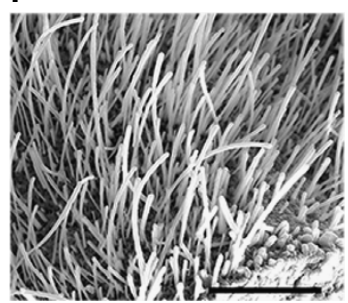

i

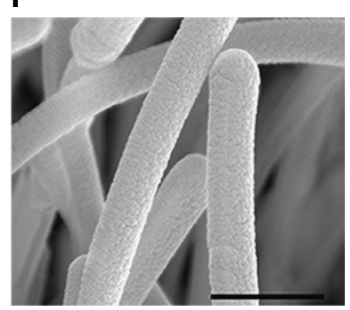

i
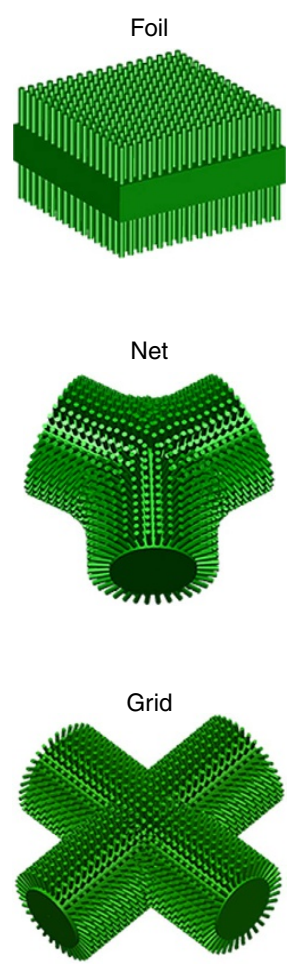

Figure 3 | Structure and morphology of the CCNEs based on various substrates. Digital images and corresponding s.e.m. micrographs of the CCNEs based on the foil $(\mathbf{a}, \mathbf{d}, \mathbf{g})$, net $(\mathbf{b}, \mathbf{e}, \mathbf{h})$ and grid $(\mathbf{c}, \mathbf{f}, \mathbf{i})$ substrates, and corresponding 3D nano-architectural models $(\mathbf{j})$. Scale bars in $\mathbf{a}-\mathbf{c}, 1 \mathrm{~cm}$; scale bars in d-f, 10 um; scale bars in $\mathbf{g - i}, 1$ um.

The crystal structure of the nanocables is observed in the high-resolution TEM of Fig. 4g. It is obvious that a wire-like $\mathrm{CuO}$ core is covered by a nanosized microporous carbon-nitride shell, and the middle of the $\mathrm{CuO}$ core is clearly divided by a (111) twin plane along the longitudinal axis, which has been reported in $\mathrm{CuO}$ nanowires synthesized via heating copper substrates in air by Jiang et al. $^{32}$. In Fig. $4 \mathrm{~h}, \mathrm{i}$, note that each side of the $\mathrm{CuO}$ core is, indeed, a single crystal with well-defined fringe space pattern. The interplanar spacing for each side is 2.32 and $2.52 \AA$, which correspond well to the (111) and ( -111$)$ spacings in monoclinic $\mathrm{CuO}$, respectively ${ }^{32-34}$. This finding is also in good agreement with the first-principle calculations that (111) and $(-111)$ planes have the lowest surface energies under ambient conditions and, hence, should be the most preferential facets of $\mathrm{CuO}$ nanowires ${ }^{35}$.

The structure and chemical composition of all samples are further characterized by X-ray diffraction (XRD), Raman spectroscopy, Fourier transform infrared spectroscopy (FT-IR) and X-ray photoelectron spectroscopy (XPS), as shown in Supplementary Fig. 2. The XRD results indicate that the obtained copper oxides nanowires have a monoclinic structure, and a weak peak at $26.2^{\circ}$ corresponds to the (002) plane of graphite-like carbon nitrides. The Raman results also confirm the single-phase property and high crystallinity of $\mathrm{CuO}$ nanowires, while in the CCNE and CNNE samples, two intense bands at 1355 and $1593 \mathrm{~cm}^{-1}$ are attributed to the D-band (disorder-induced phonon mode) and G-band (graphite band) of carbon nitrides, respectivel ${ }^{36}$. It is generally accepted that the intensity ratio $\mathrm{I}_{\mathrm{D}} / \mathrm{I}_{\mathrm{G}}$ can be used to estimate the degree of disorder in carbon materials ${ }^{37}$. Note that the $\mathrm{I}_{\mathrm{D}} / \mathrm{I}_{\mathrm{G}}$ ratio of the $\mathrm{CNNE}$ is higher than that of the CCNE, indicating that the thermal reduction process generates extrinsic defects in the carbon-nitride framework. The FT-IR analysis reveals the oxidation of $\mathrm{Cu}^{2+}$ in the $\mathrm{CuO}$ nanowires and the graphitic structure of the $\mathrm{CN}_{x}$ film. The XPS analysis provides further evidence for the significant chemical nature of nitrogen incorporation in the carbon matrix. In the $\mathrm{N}$ spectrum, the peak shows an asymmetry, where the major component at $398.7 \mathrm{eV}$ is due to the pyridinic nitrogen, and shoulder peaks at $400.1-401.2 \mathrm{eV}$ are assigned to the pyrrolic nitrogen in the terminal $\mathrm{C}-\mathrm{N}$ groups and quaternary nitrogen in the graphite $\mathrm{C}-\mathrm{N}$ bonds ${ }^{36,38}$. This finding indicates that the nitrogen-substituted carbon creates more pyridine- and pyrrolelike defects in the carbon framework and generates more active sites for the Li storage. Due to the higher electronegativity of nitrogen (3.5) than carbon (3.0), and its smaller diameter, the stronger interaction between the carbon nitrides and $\mathrm{Li}$ also facilitates the penetration of $\mathrm{Li}$ across the defects ${ }^{36,37,39}$. Further details on chemical and structural characterization can be found in Supplementary Note 1.

Electrochemical properties. The battery performance of our hierarchical structured electrode is evaluated by galvanostatic charge-discharge cycling of the 2025 coin-type cells. Half-cells with a metallic $\mathrm{Li}$ counter electrode are used to evaluate electrochemical properties of these nanocomposite electrodes. In Fig. $5 \mathrm{a}$, the cells are run at a current density of $50 \mathrm{mAg} \mathrm{g}^{-1}$; the CNE, CCNE, and CNNE based on grid substrates deliver an initial discharge capacity of $1234.8,1164.8$ and $1355.6 \mathrm{mAh} \mathrm{g}^{-1}$, respectively. In the next cycle, the reversible discharge capacity of the CNE, CCNE and CNNE is $692.9,803.6$ and $801.8 \mathrm{mAh} \mathrm{g}^{-1}$, respectively, with capacity retention of 56.2, 69.0 and $59.1 \%$, respectively. These results suggest that the $\mathrm{CuO}$ core and $\mathrm{CN}_{x}$ shell in the nanocables both provide deintercalation capacity, and that the CCNE with core-shell architecture exhibits the highest 
a

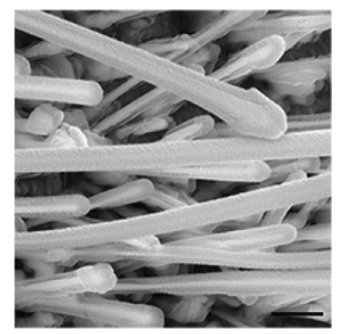

e

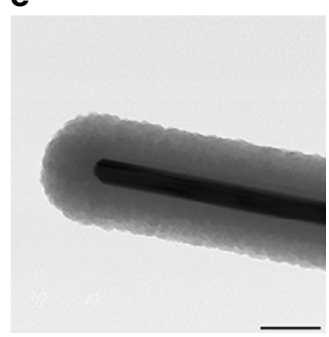

f
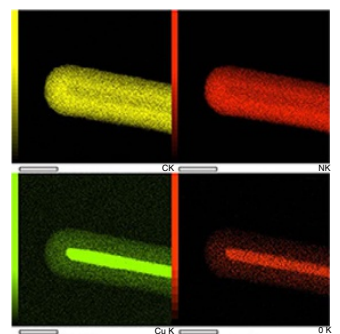

b

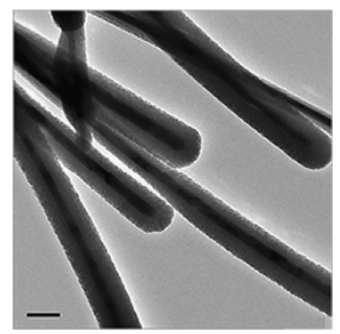

g

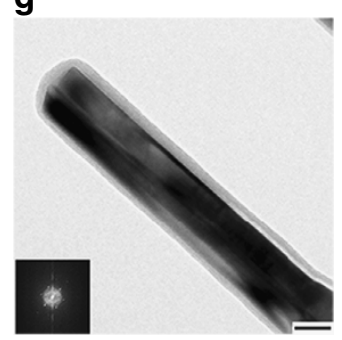

j
C

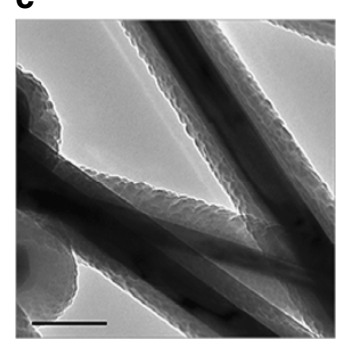

h

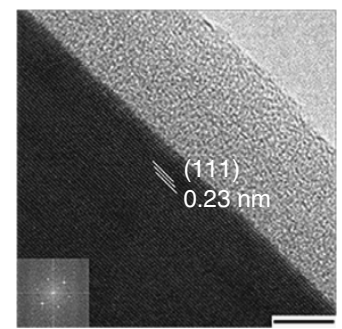

d

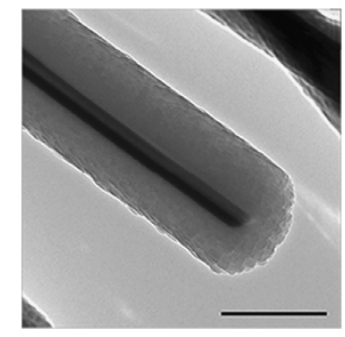

i

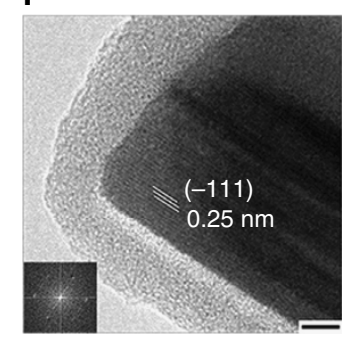

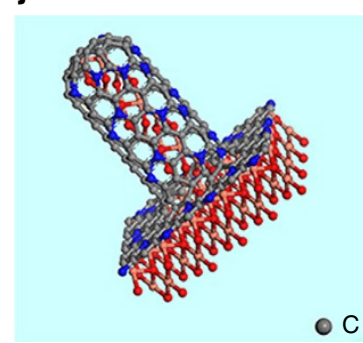
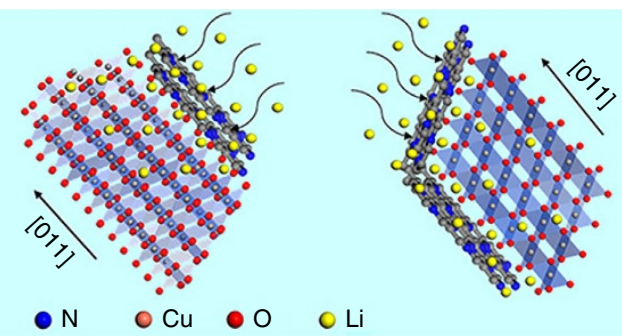

Figure 4 | Core-shell structure of the CCNEs. s.e.m. (a) and TEM (b) micrographs of the CCNE after 30 min deposition. TEM micrographs of the CCNEs after $20 \mathrm{~min}$ (c) and $40 \mathrm{~min}$ (d) deposition. STEM image (e) and EDX elemental mapping (f) of the core-shell nanocable. High-resolution TEM images (g-i) of the nanoscale after 5 min deposition, and corresponding micro-mechanism models (j). Scale bar in a, 1 um; scale bars in b-f, $200 \mathrm{~nm}$; scale bar in $\mathbf{g}, 40 \mathrm{~nm}$; scale bars in $\mathbf{h}$ and $\mathbf{i}, 5 \mathrm{~nm}$.

reversible capacity and capacity retention. The extra capacity above the theoretical value of $\mathrm{CuO}\left(670 \mathrm{mAh} \mathrm{g}^{-1}\right)$ is believed to be due to the reductive decomposition of the electrolyte and subsequent formation of solid-electrolyte interphase (SEI) layers, which are inferred from cyclic voltammetry (Supplementary Fig. 3 and Supplementary Note 2). The SEI layers covering the surface of active nanocomposites prevent further reaction between the components of the electrolyte and the active materials ${ }^{40}$. However, note that there is a large initial capacity loss, especially for the CNE and CNNE, which is due to the high surface areas of nanowire arrays. Figure $5 \mathrm{~b}$ shows the cycle performance over 200 cycles of different nanocomposite electrodes based on the grid substrate. From the 2nd to the 200th cycle, their capacity retention is $44.0,83.3$ and $73.8 \%$, respectively. After 200 cycles, the CCNE still delivers a high capacity of $669.0 \mathrm{mAh}^{-1}$, which is almost twice the theoretical capacity of graphite and also higher than that of the CNE $\left(305.1 \mathrm{mAh} \mathrm{g}^{-1}\right)$ and CNNE $\left(592.1 \mathrm{mAh} \mathrm{g}^{-1}\right)$. Also note that the coulombic efficiency of the CCNE rapidly increases to ca. $99 \%$ after the first 5 cycles, and remains stable throughout the cycles, indicating that the SEI layers remain intact, allowing reversible cycling after the surface reactions are completed. This result suggests that the CCNE shows the highest reversible capacity and the best cycle performance, indicating electrochemical reversibility and structural stability. Figure $5 \mathrm{c}$ shows rate performance versus cycle life. In general, the capacity retention of all electrodes decreases with increasing current density from 50 to $2500 \mathrm{mAg}^{-1}$. Compared with the CNE, the
CCNE and CNNE show better stability on cycling at each current rate, and almost recover their original capacity values when the current density is restored to $50 \mathrm{~mA} \mathrm{~g}^{-1}$. At the current density of $2,500 \mathrm{mAg}^{-1}$, the CNE, CCNE and CNNE deliver an average discharge capacity of $230.5,553.7$ and $500.3 \mathrm{mAhg}^{-1}$, respectively. The rate performance exhibited, particularly by CCNE, is excellent for a metal oxide anode. This finding reveals that the CCNE shows good charge transfer kinetics and stable structural integrity. The reductive CNNE also exhibits good electrochemical performance as a promising carbon-nitride candidate for anode materials. It is likely that the high $\mathrm{N}$ doping in the $\mathrm{CN}_{x}$ layer ( $\sim 20$ at\%, in this work) creates abundant defects that are well known to increase the capacity of the engineered carbon for their fast reaction with lithium ${ }^{37}$. Moreover, the $\mathrm{N}$ doping can also enhance the electronic conductivity, which additionally contributes to the exceptional rate performance ${ }^{38}$. However, initial coulomic efficiency and cyclability is poorer in CNNE than in CCNE, mainly due to the morphological/structural changes during the thermal reduction, which yield higher surface areas and reduce the structural stability of the CNNE (Supplementary Fig. 4).

We investigated the effect of the different substrates on the cell performance. Figure $6 \mathrm{a}, \mathrm{b}$ show a set of parallel charge-discharge profiles and capacity retention over 200 cycles for comparison, respectively. The initial discharge capacity of the CCNE based on the foil, grid and net is $1134.1,1164.8$ and $1190.6 \mathrm{mAhg}^{-1}$, respectively. After 200 cycles, their remainder capacity is 610.9, 669.0 and $717.7 \mathrm{mAh} \mathrm{g}^{-1}$, respectively. The CCNEs based on the 
a

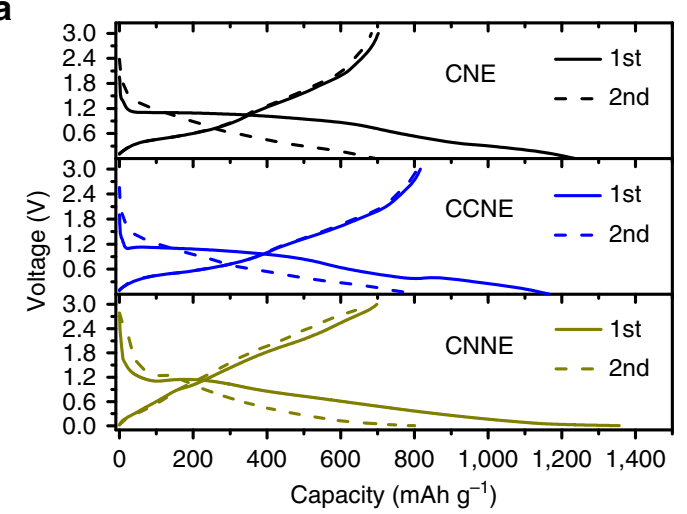

C

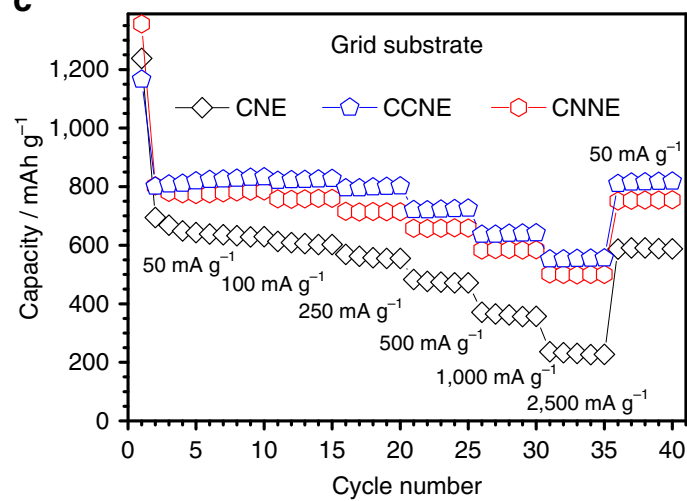

b

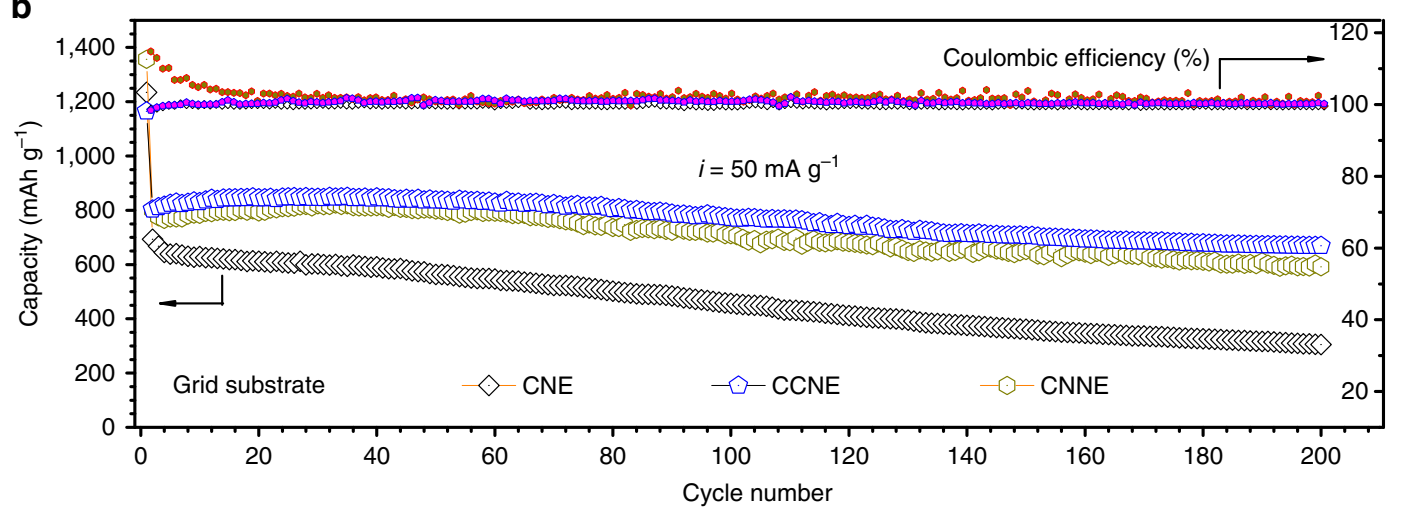

Figure 5 | Electrochemical characterization of nanocomposite anodes in half-cells. Voltage profiles (a), cycle performance (b) and rate performance (c) for CNE, CCNE and CNNE samples based on the grid substrate. (In this and subsequent figures, all specific capacities of CCNEs are based on the total mass of the active materials contain $\mathrm{CuO}$ and $\mathrm{CN}_{x}$ in the core-shell structure).
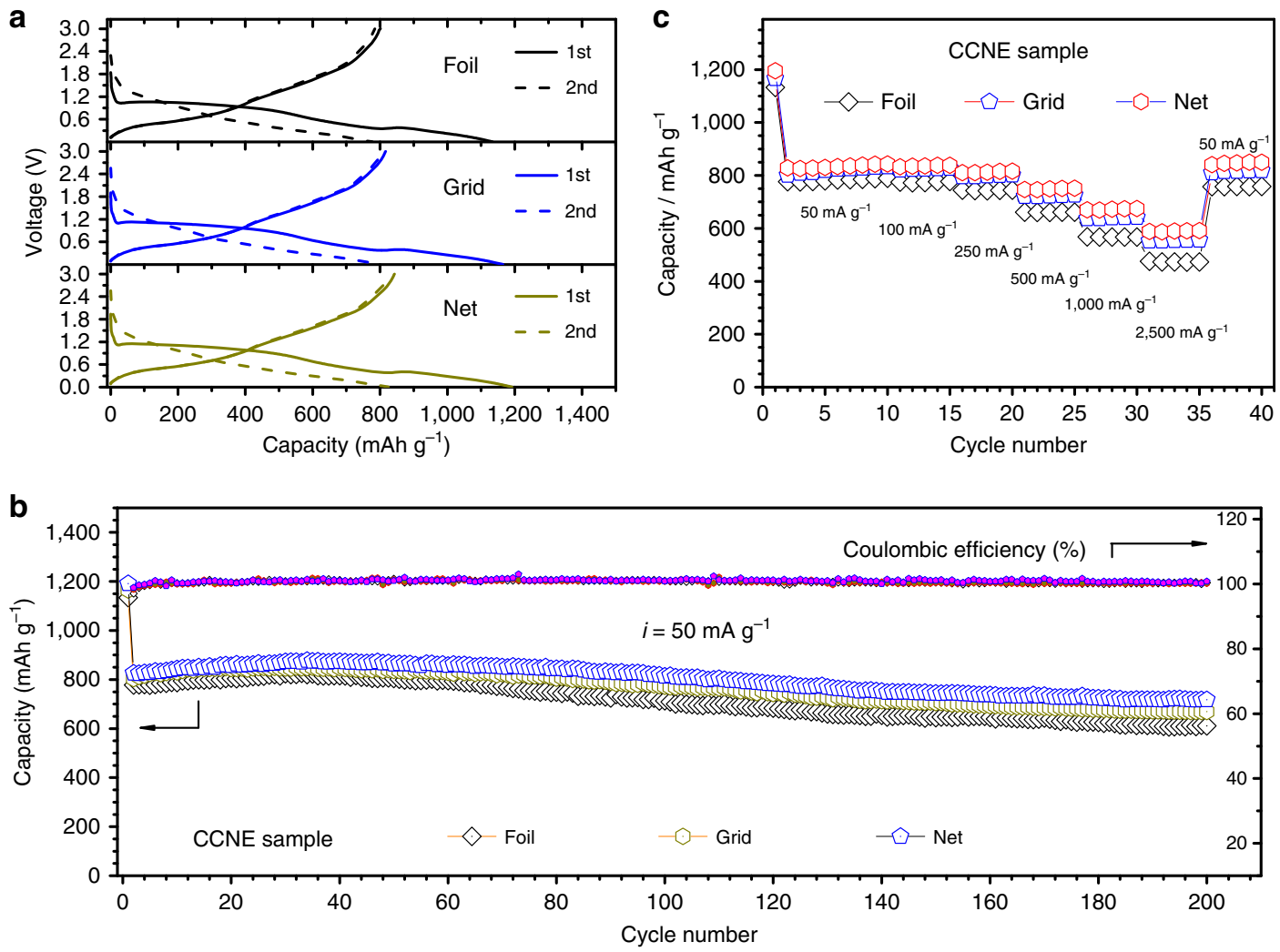

Figure 6 | Electrochemical characterization of CCNEs in half-cells. Voltage profiles (a), cycle performance (b) and rate performance (c) for CCNEs based on the foil, grid and net substrates. 
grid and net deliver higher reversible discharge capacities and coulombic efficiency than those of the foil. This difference is due to the larger specific surface area and more abundant transfer paths in the grid and net substrates, which provide extra space for diffusion of the electrolyte and accommodation of the strain induced by the volume change during the electrochemical reaction, thus leading to higher charge transfer efficiency and better structural stability ${ }^{4}$. Figure $6 \mathrm{c}$ shows the rate cycling performance of these cells. The capacity and rate performance are also gradually improved as the specific surface area increases. The net sample shows the highest capacity, $589.6 \mathrm{mAhg}^{-1}$, at the current density of $2500 \mathrm{mAg}^{-1}$. These results indicate that the morphologies of the nanosubstrates have a significant effect on the cell performance.

We also analysed the effect of the deposited thickness of the $\mathrm{CN}_{x}$ shell on cell performance. Figure $7 \mathrm{a}$ shows the cycle performance of all CCNEs with different deposition times from 5 to $50 \mathrm{~min}$. The reversible capacity gradually improves as the deposition time increases until $30 \mathrm{~min}$. However, the capacity slightly decreases when the time increases to $40-50 \mathrm{~min}$, which reveals an optimal thickness of the $\mathrm{CN}_{x}$ shell depositing on the $\mathrm{CuO}$ core. The longer time introduces a thicker $\mathrm{CN}_{x}$ shell, which retards the infiltration of the electrolyte into the $\mathrm{CuO}$ core, resulting in the decreasing charge transfer efficiency. Note that the cycle performance is improved as the deposition time increases, which indicates that the thicker $\mathrm{CN}_{x}$ shell brings better structural stability.

Full cells with the commercial $\mathrm{LiCoO}_{2}$ as the cathode and electrochemically activated nanocomposites (CNE, CCNE or CNNE) as the anode are fabricated to evaluate the battery performance. Figure $7 \mathrm{~b}$ shows the cycling performance of these coin-type full cells. The working voltage of the full cells ranges from 2.4 to $3.6 \mathrm{~V}$, and the current density is $15 \mathrm{~mA} \mathrm{~g}^{-1}$. Based on the grid substrates, the $\mathrm{CNE} / \mathrm{LiCoO}_{2}$ cell delivers an initial discharge capacity of $141 \mathrm{mAhg}^{-1}$ (the reversible capacity of $\mathrm{LiCoO}_{2}$ is $155 \mathrm{mAhg}^{-1}$ when it is cycled between 3 and $4.4 \mathrm{~V}$ versus $\mathrm{Li}$ metal). The capacity fades to $136 \mathrm{mAh} \mathrm{g}^{-1}$ after 100 cycles, with $96.4 \%$ capacity retention. Comparatively, the $\mathrm{CCNE} / \mathrm{LiCoO}_{2}$ and $\mathrm{CNNE} / \mathrm{LiCoO}_{2}$ cells show slightly increased reversible capacities and more stable cycle performance. However, there is no obvious difference among the capacities of the full cells. This result is due to the cathode-limited design, in which the cell utilizes under stable conditions only a fraction of the capacity offered by the anode, with the cell capacity balance leading to optimal cell behaviour ${ }^{42,43}$.

Mechanism analysis. The above results demonstrate that the electrode structural design of $3 \mathrm{D}$ arrays with core-shell nano-architecture can achieve stable performance in metal oxide anodes. Such a design has multiple advantages: First, the nitrogen-incorporated carbon framework functions as an electrical highway and ${\mathrm{a} \mathrm{Li}^{+}}^{+}$absorbent, so that the $\mathrm{CuO} / \mathrm{CN}_{x}$ nanocables are electrochemically active. Figure $4 \mathrm{j}$ illustrates the micro-mechanism models of the nanocable, where the wire-like $\mathrm{CuO}$ core is a bicrystal divided by a (111) twin plane in the direction parallel to the longitudinal axis. Density functional theory calculations (Supplementary Fig. 5) display surface atomic configurations in (001), (100), (110), (111) and ( - 111) planes of the $\mathrm{CuO}$ unit cell, where the $(111)$ and $(-111)$ planes contain more $\mathrm{Cu}^{2+}$ than other surfaces ${ }^{44}$. According to the positive linear relationship between the electrochemical performance of
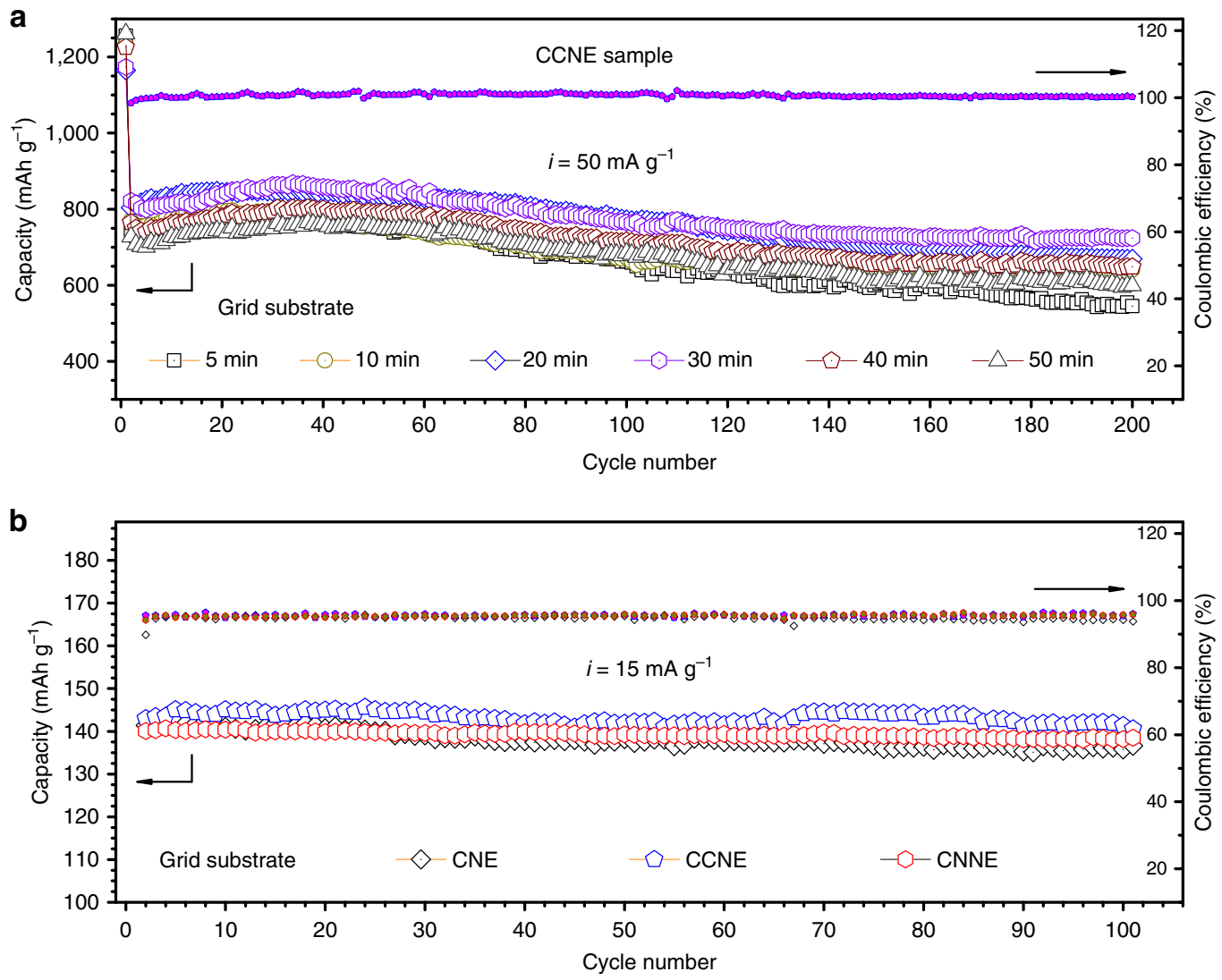

Figure 7 | Electrochemical characterization of nanocomposite electrodes. (a) Cycle performance for CCNEs based on the grid substrate in half-cells with different deposition times. (b) Cycle performance of the full cells containing nanocomposite anodes based on the grid substrate. 
a

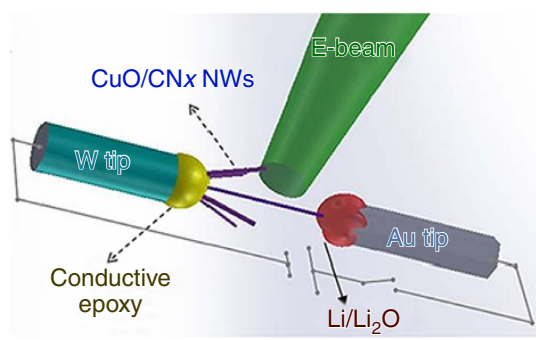

C

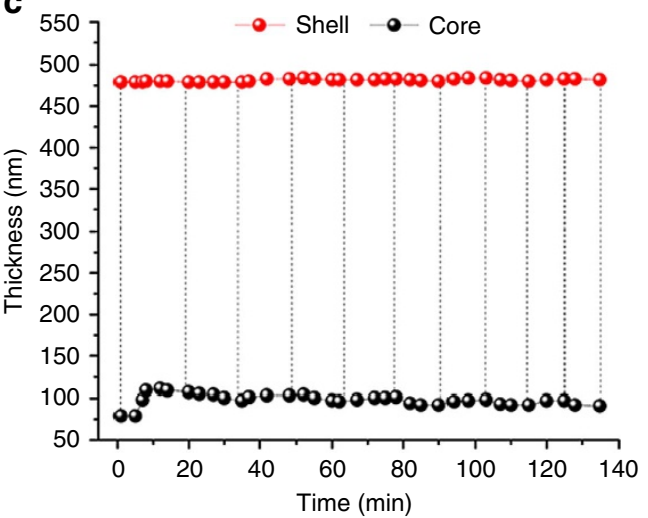

b

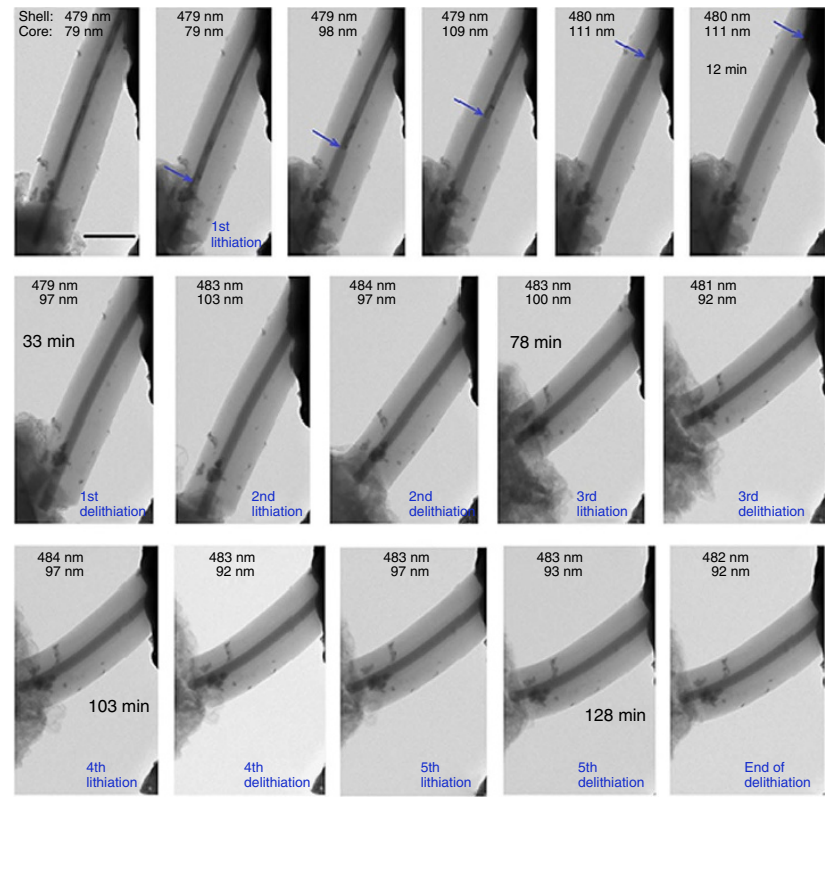

Figure 8 | In situ TEM characterization of the CCNE nanocable during lithiation and delithiation. (a) Schematic of the in situ TEM device. (b) Time-lapse TEM images of single CCNE nanocable during lithiation and delithiation. (c) Thickness variation curves of the CCNE nanocable during lithiation - delithiation cycles. Scale bar in b, $400 \mathrm{~nm}$.

$\mathrm{CuO}$ and the redox reaction of $\mathrm{Cu}^{2+} / \mathrm{Cu}^{0}$, the $\mathrm{CuO}$ nanowires with more exposed (111) twin planes induce more and faster $\mathrm{Cu}^{2+} / \mathrm{Cu}^{0}$ redox reaction, bringing higher reversible capacity and better rate capability. The (111) twin planes are also much more stable than other planes ${ }^{35}$, thus exhibiting better cycle performance. Moreover, the microporous $\mathrm{CN}_{x}$ shell with high nitrogen contents induces numerous pyridine- and pyrrole-like defects, adds $\mathrm{Li}$ insertion sites and it thus enhances Li storage capacity. Second, core-shell nano-architecture prevents fracture, where the $\mathrm{CuO}$ core is stabilized mechanically by the $\mathrm{CN}_{x}$ shell. The elastic $\mathrm{CN}_{x}$ layers are also believed to stabilize the electrode/ electrolyte interface and thus effectively enhance the cycle stability and high rate capability ${ }^{38,39,45}$. This theory has been confirmed by in situ TEM measurements (Fig. 8, Supplementary Figs 6 and 7, and Supplementary Movie 1) of CCNE nanocables during lithiation and delithiation. Figure 8a illustrates the nanobattery for in situ TEM observation. Figure 8b shows a single CCNE nanocable lithiated and delithiated five times. During the initial lithiation, snapshots show a progressive lithiation mainly along the axial direction of the nanocable, where the lithiation of $\mathrm{CuO}$ nanowire proceeds both axially and radially, but the whole volume of the nanocable shows no evident expansion due to the mechanical buffering effect of microporous $\mathrm{CN}_{x}$ shell. Figure $8 \mathrm{c}$ shows the thickness variation of the nanocable during lithiation - delithiation cycles. The $\mathrm{CuO}$ core has an evident volume expansion by $\sim 93 \%$ during initial lithiation, but then its dimensions appear to stabilize during the next few cycles. Note that the thickness of the whole shell has no evident change during the cycles, indicating a good structural integrity of the nanocable electrode during electrochemical reactions. Third, 3D arrays with larger surface areas, better permeability and more active sites provide ideal conditions for the facile diffusion of the electrolyte and accommodation of the volumetric strain during electrochemical reactions, thus leading to higher charge transfer efficiency. The nanocable arrays directly grown on current collectors have good adhesion and electrical contact, reduce the path length of $\mathrm{Li}^{+}$ions and electron transfer and enhance the rate capability. Fourth, the monolithic sandwich structure ensures a stable structural integrity, which prevents the electrodes from pulverization and fragmentation. It does not contain additional conductive agents or binders, and this condition improves the energy and power densities of the whole electrode. This structure also enhances the electrical contact with the current collector when it is assembled into cells. In summary, this hierarchical 3D core-shell nanostructure guarantees excellent structural properties and superior electrochemical performance.

\section{Discussion}

Since the pioneering work of metal oxides anodes for lithium ion batteries by Tarascon in 2001 (ref. 16), more conversion materials including oxides, nitrides, fluorides and sulfides have been developed as anodes. Similar to alloy anodes, conversion anodes often suffer from low initial efficiency and severe capacity fading, originating from causes such as unstable SEI layers, material structural degradation and large volume change. Here we design a specific large-scale hierarchical structured electrode assembly, a freestanding 3D array of core-shell nanostructures, to tackle these issues. Based on above material characterizations and electrochemical measurements, the $3 \mathrm{D} \mathrm{CuO} / \mathrm{CN}_{x}$ core-shell nanoarchitecture combines features that are simultaneously attractive for electronic, mechanical and electrochemical properties necessary for stable cycling and high coulombic efficiency. The $\mathrm{CN}_{x}$ shell encapsulates the $\mathrm{CuO}$ electrode, limiting most SEI formation to the outer surface instead of directly on $\mathrm{CuO}$ active materials; at the same time, the core-shell nanostructure helps reversible accommodation of the volume change of the $\mathrm{CuO}$ active material. Similar approaches have also been reported in CuO@graphene and Si@C composites ${ }^{46-48}$. 
In the full-cell design, both cathode-limited capacity design and electrochemical prelithiation technique for the nanocomposite anodes are used to address the impact of initial capacity loss in the anode. These techniques have been well investigated and are now widely used, particularly for cells employing alloy and conversion anode materials ${ }^{42,43}$. The electrode structures developed here thus show promise for use in advanced lithium-ion batteries, and also have broader potential to be adopted for flexible energy storage devices.

In conclusion, we have developed battery electrodes combining a flexible design and 3D hierarchical nanostructures. The specific combination of composition and conformation addresses stability challenges common to many conversion electrodes and may be generalized to related systems. In addition, the simple fabrication process involving mature sputtering technology boosts prospects for scaleable production.

\section{Methods}

Synthesis of 3D CuO nanosubstrates. Commercially available copper foils (99.9\% purity, $0.1 \mathrm{~mm}$ thick), copper grids (99.9\% purity, 600 mesh) and copper nets $(99.9 \%$ purity, 600 mesh) were used as the starting substrates to synthesize $3 \mathrm{D}$ $\mathrm{CuO}$ nanosubstrates through a vapor-phase approach ${ }^{32}$. In a typical procedure, copper substrates were cleaned in an aqueous $1.0 \mathrm{M} \mathrm{HCl}$ solution for $10 \mathrm{~min}$, followed by repeated rinsing with distilled water. After they had been dried under a $\mathrm{N}_{2}$ gas flow, they were immediately heated to $600^{\circ} \mathrm{C}$ for $5 \mathrm{~h}$ under an oxygen atmosphere in a tubular electrical furnace. In addition, $\mathrm{CuO}$ nanowires of similar quality were grown on the surfaces of all these copper substrates.

Synthesis of 3D $\mathbf{C u O} / \mathrm{CN}_{\mathbf{x}}$ nanocomposites. A nanosized $\mathrm{CN}_{x}$ film was deposited onto $\mathrm{CuO}$ nanosubstrates by radio-frequency magnetron sputtering using a graphite target at $80 \mathrm{~W}$ and $1.0 \mathrm{~Pa}$ in a $\mathrm{N}_{2}$ atmosphere. The chamber was evacuated to a base pressure of $1.0 \times 10^{-5} \mathrm{~Pa}$ to guarantee a clean sputtering condition. The target was pre-sputtered for $15 \mathrm{~min}$ to eliminate impurities. The deposition time was set in a stepwise manner to $5,10,20,30,40,50$ and $60 \mathrm{~min}$.

Synthesis of 3D $\mathbf{C u} / \mathbf{C N}_{\mathbf{x}}$ nanocomposites. The obtained $\mathrm{CuO} / \mathrm{CN}_{x}$ nanocomposites were heat treated at $300{ }^{\circ} \mathrm{C}$ for $2 \mathrm{~h}$ under a $\mathrm{H}_{2} / \mathrm{Ar}\left(10 \% \mathrm{H}_{2}\right.$ in volume $)$ atmosphere at flow rate of $100 \mathrm{ml} \mathrm{min}^{-1}$ in a tubular electrical furnace.

Characterization. The s.e.m. investigations were performed on a FEI QUANTA-250 operated at an acceleration voltage of $15 \mathrm{kV}$. The TEM observations were conducted with a JEOL-2010 microscope operated at $200 \mathrm{kV}$ and a JEM-ARM200F microscope equipped with an EDX energy-dispersive spectrometer. The XRD patterns were recorded using a Rigaku Ultima IV-185 $\mathrm{X}$-ray diffractometer $(\mathrm{Cu}-\mathrm{Ka}$ radiation, $\lambda=1.5406 \AA, 40 \mathrm{kV}$ and $40 \mathrm{~mA}$ ) at a scanning rate of $0.2^{\circ} \mathrm{s}^{-1}$. The FT-IR spectra were obtained on a Nicolet 6700 infrared spectrometer. Raman spectra were recorded on a Labram HR 800 Raman microscope. The XPS spectra were acquired on a PHI Quantera. The in situ electrochemical lithiation - delithiation observations were carried out inside JEOL 3010 TEM operated at $300 \mathrm{KeV}$.

Electrochemistry. The battery performance was evaluated by galvanostatic cycling of 2025 coin-type cells. The half-cell was made up of nanocomposites as the working electrode and lithium foil as the counter electrode. The full cell was composed of commercial $\mathrm{LiCoO}_{2}$ as the cathode and nanocomposites as the anode. The electrolyte was $1.0 \mathrm{M} \mathrm{LiPF}_{6}$ in $1: 1$ ratio by volume of ethylene carbonate/ dimethyl carbonate. A Celgard 2400 membrane was employed as the separator. Before assembling the full cells, nanocomposite anodes were electrochemically activated for three cycles in half-cells to eliminate the capacity loss in the first cycle. Being a cathode-limited design, the cell balance value (the capacity ratio of the anode to the cathode) is designed to be $>1$ to ensure efficient utilization of the cathode materials. The cells were assembled in an Ar-filled glove box, then aged for $24 \mathrm{~h}$ before the electrochemical tests. Cyclic voltammetry and electrochemical impedance spectroscopy measurements were performed on a ZAHNER PP211 electrochemical workstation. Galvanostatic charge-discharge tests were carried out with a Land CT2001A battery tester. The weight of the $\mathrm{CuO}$ active materials was determined by subtracting the weight of the residual $\mathrm{Cu}$ substrate from the overall weight of the CNE, by using a hydrochloric acid corrosion method. The weight of the $\mathrm{CN}_{x}$ coating layer was determined by subtracting the weight of the CNE from the overall weight of CCNE. Supplementary Table 1 illustrates the areal masses of all the nanocomposite electrodes. For the CCNEs, the specific capacity was calculated based on the total mass of $\mathrm{CuO} / \mathrm{CN}_{x}$ active materials. All of the weight values were obtained with a high-precision BT $25 \mathrm{~S}$ electronic balance.

\section{References}

1. Armand, M. \& Tarascon, J. M. Building better batteries. Nature 451, 652-657 (2008).

2. Sathiya, M. et al. Reversible anionic redox chemistry in high-capacity layeredoxide electrodes. Nat. Mater. 12, 827-835 (2013).

3. Wu, F. et al. Stable nanostructured cathode with polycrystalline Li-deficient $\mathrm{Li}_{0.28} \mathrm{Co}_{0.29} \mathrm{Ni}_{0.30} \mathrm{Mn}_{0.20} \mathrm{O}_{2}$ for lithium-ion batteries. Nano Lett. 14, 1281-1287 (2014).

4. Wu, F. et al. Novel solid-state $\mathrm{Li} / \mathrm{LiFePO}_{4}$ battery configuration with a ternary nanocomposite electrolyte for practical applications. Adv. Mater. 23, 5081-5085 (2011).

5. Guo, B. et al. Soft-templated mesoporous carbon-carbon nanotube composites for high performance lithium-ion batteries. Adv. Mater. 23, 4661-4666 (2011).

6. Aricò, A. S., Bruce, P., Scrosati, B., Tarascon, J.-M. \& van Schalkwijk, W. Nanostructured materials for advanced energy conversion and storage devices. Nat. Mater. 4, 366-377 (2005).

7. Bruce, P. G., Scrosati, B. \& Tarascon, J.-M. Nanomaterials for rechargeable lithium batteries. Angew. Chem. Int. Ed. 47, 2930-2946 (2008)

8. Li, H., Wang, Z., Chen, L. \& Huang, X. Research on advanced materials for Li-ion batteries. Adv. Mater. 21, 4593-4607 (2009).

9. Cheng, F., Liang, J., Tao, Z. \& Chen, J. Functional materials for rechargeable batteries. Adv. Mater. 23, 1695-1715 (2011).

10. Jeong, G., Kim, Y.-U., Kim, H., Kim, Y.-J. \& Sohn, H.-J. Prospective materials and applications for Li secondary batteries. Energy Environ. Sci. 4, 1986-2002 (2011).

11. Chen, Z., Belharouak, I., Sun, Y.-K. \& Amine, K. Titanium-based anode materials for safe lithium-ion batteries. Adv. Funct. Mater. 23, 959-969 (2013).

12. Reddy, M. V., Subba Rao, G. V. \& Chowdari, B. V. R. Metal oxides and oxysalts as anode materials for $\mathrm{Li}$ ion batteries. Chem. Rev. 113, 5364-5457 (2013).

13. Yuan, C., Wu, H. B., Xie, Y. \& Lou, X. W. Mixed transition-metal oxides: Design, synthesis, and energy-related applications. Angew. Chem. Int. Ed. 53, 1488-1504 (2014).

14. Kim, M. G. \& Cho, J. Reversible and high-capacity nanostructured electrode materials for Li-ion batteries. Adv. Funct. Mater. 19, 1497-1514 (2009).

15. Cabana, J., Monconduit, L., Larcher, D. \& Palacín, M. R. Beyond intercalationbased Li-ion batteries: The state of the art and challenges of electrode materials reacting through conversion reactions. Adv. Mater. 22, E170-E192 (2010).

16. Poizot, P., Laruelle, S., Grugeon, S., Dupont, L. \& Tarascon, J.-M. Nano-sized transition-metal oxides as negative-electrode materials for lithium-ion batteries. Nature 407, 496-499 (2000).

17. Lee, K. T. \& Cho, J. Roles of nanosize in lithium reactive nanomaterials for lithium ion batteries. Nano Today 6, 28-41 (2011).

18. Wu, H. B., Chen, J. S., Hng, H. H. \& Lou, X. W. Nanostructured metal oxide-based materials as advanced anodes for lithium-ion batteries. Nanoscale 4, 2526-2542 (2012).

19. Nam, K. T. et al. Virus-enabled synthesis and assembly of nanowires for lithium ion battery electrodes. Science 312, 885-888 (2006).

20. Chen, J. \& Cheng, F. Combination of lightweight elements and nanostructured materials for batteries. Acc. Chem. Res. 42, 713-723 (2009).

21. Ji, L., Lin, Z., Alcoutlabi, M. \& Zhang, X. Recent developments in nanostructured anode materials for rechargeable lithium-ion batteries. Energy Environ. Sci. 4, 2682-2699 (2011).

22. Wang, Z., Zhou, L. \& Lou, X. W. Metal oxide hollow nanostructures for lithium-ion batteries. Adv. Mater. 24, 1903-1911 (2012).

23. Li, J., Tang, S., Lu, L. \& Zeng, H. C. Preparation of nanocomposites of metals, metal oxides, and carbon nanotubes via self-assembly. J. Am. Chem. Soc. 129, 9401-9409 (2007).

24. Hou, Y., Cheng, Y. W., Hobson, T. \& Liu, J. Design and synthesis of hierarchical $\mathrm{MnO}_{2}$ nanospheres/carbon nanotubes/conducting polymer ternary composite for high performance electrochemical electrodes. Nano Lett. 10, 2727-2733 (2010).

25. Wang, D. et al. Ternary self-assembly of ordered metal oxide-graphene nanocomposites for electrochemical energy storage. ACS Nano 4, 1587-1595 (2010).

26. Ko, S., Lee, J., Yang, H. S., Park, S. \& Jeong, U. Mesoporous CuO particles threaded with CNTs for high-performance lithium-ion battery anodes. $A d v$ Mater. 24, 4451-4456 (2012).

27. Zhang, Q. et al. $\mathrm{CuO}$ nanostructures: synthesis, characterization, growth mechanisms, fundamental properties, and applications. Prog. Mater. Sci. 60, 208-337 (2014).

28. Wang, C. et al. Controlled synthesis of micro/nanostructured $\mathrm{CuO}$ anodes for lithium-ion batteries. Nano Energy 9, 334-344 (2014).

29. Wang, C. et al. Morphology-dependent performance of $\mathrm{CuO}$ anodes via facile and controllable synthesis for lithium-ion batteries. ACS Appl. Mater. Interfaces 6, 1243-1250 (2014).

30. Tabernal, P. L., Mitra, S., Poizot, P., Simon, P. \& Tarascon, J.-M. High rate capabilities $\mathrm{Fe}_{3} \mathrm{O}_{4}$-based $\mathrm{Cu}$ nano-architectured electrodes for lithium-ion battery applications. Nat. Mater. 5, 567-573 (2006). 
31. Jiang, J., Li, Y., Liu, J. \& Huang, X. Building one-dimensional oxide nanostructure arrays on conductive metal substrates for lithium-ion battery anodes. Nanoscale 3, 45-58 (2011).

32. Jiang, X., Herricks, T. \& Xia, Y. CuO nanowires can be synthesized by heating copper substrates in air. Nano Lett. 2, 1333-1338 (2002).

33. Liu, B. \& Zeng, H. C. Mesoscale organization of $\mathrm{CuO}$ nanoribbons: formation of 'dandelions'. J. Am. Chem. Soc. 126, 8124-8125 (2004).

34. Bao, H. et al. Crystal-plane-controlled surface restructuring and catalytic performance of oxide nanocrystals. Angew. Chem. Int. Ed. 50, 12294-12298 (2011).

35. Hu, J., Li, D., Lu, J. G. \& Wu, R. Effects on electronic properties of molecule adsorption on $\mathrm{CuO}$ surfaces and nanowires. J. Phys. Chem. C 114, 17120-17126 (2010).

36. Mao, Y. et al. Lithium storage in nitrogen-rich mesoporous carbon materials. Energy Environ. Sci. 5, 7950-7955 (2012).

37. Li, Z. et al. Mesoporous nitrogen-rich carbons derived from protein for ultra-high capacity battery anodes and supercapacitors. Energy Environ. Sci. 6, 871-878 (2013).

38. Qie, L. et al. Nitrogen-doped porous carbon nanofiber webs as anodes for lithium ion batteries with a superhigh capacity and rate capability. Adv. Mater. 24, 2047-2050 (2012).

39. Wang, H. et al. Nitrogen-doped graphene nanosheets with excellent lithium storage properties. J. Mater. Chem. 21, 5430-5434 (2011).

40. Maier, J. Nanoionics Ion transport and electrochemical storage in confined systems. Nat. Mater. 4, 805-815 (2005).

41. Liu, B. et al. Hierarchical three-dimensional $\mathrm{ZnCo}_{2} \mathrm{O}_{4}$ nanowire arrays/carbon cloth anodes for a novel class of high-performance flexible lithium-ion batteries. Nano Lett. 12, 3005-3011 (2012).

42. Verrelli, R., Hassoun, J., Farkas, A., Jacobb, T. \& Scrosati, B. A new, high performance $\mathrm{CuO} / \mathrm{LiNi}_{0.5} \mathrm{Mn}_{1.5} \mathrm{O}_{4}$ lithium-ion battery. J. Mater. Chem. A 1, 15329-15333 (2013).

43. Jayaraman, S. et al. Ultralong durability of porous $\alpha-\mathrm{Fe}_{2} \mathrm{O}_{3}$ nanofibers in practical Li-ion configuration with $\mathrm{LiMn}_{2} \mathrm{O}_{4}$ cathode. Adv. Sci. 2, 50-54 (2015).

44. Fei, Z., Lu, P., Feng, X., Sun, B. \& Ji, W. Geometrical effect of CuO nanostructures on catalytic benzene combustion. Catal. Sci. Technol. 2 1705-1710 (2012).

45. Zhao, L., Hu, Y.-S., Li, H., Wang, Z. \& Chen, L. Porous $\mathrm{Li}_{4} \mathrm{Ti}_{5} \mathrm{O}_{12}$ coated with $\mathrm{N}$-doped carbon from ionic liquids for Li-ion batteries. Adv. Mater. 23, 1385-1388 (2011).

46. Guan, C. et al. Highly stable and reversible lithium storage in $\mathrm{SnO}_{2}$ nanowires surface coated with a uniform hollow shell by atomic layer deposition. Nano Lett. 14, 4852-4858 (2014).

47. Zhu, C. et al. Enhanced lithium storage performance of $\mathrm{CuO}$ nanowires by coating of graphene quantum dots. Adv. Mater. Interfaces 2, 499-504 (2015).
48. Liu, N. et al. A pomegranate-inspired nanoscale design for large-volume-charge lithium battery anodes. Nat. Nanotechnol. 9, 187-192 (2014).

\section{Acknowledgements}

This work was supported by the U.S. Department of Energy under Contract DE-AC0206CH11357 with the support provided by the Vehicle Technologies Office, Department of Energy (DOE) Office of Energy Efficiency and Renewable Energy (EERE) This work was also supported by Major achievements Transformation Project for Centra University in Beijing, the National Basic Research Program of China (2015CB251100) and National Science Foundation of China (21373028). R.S.-Y. and Y.F.Y. acknowledge the funding support from National Science Foundation (NSF-DMR-1620901) for their efforts on in-situ TEM. Partial funding from Argonne National Laboratory for Y.F.Y. under subcontract No. 4J-30361 is also acknowledged.

\section{Author contributions}

G.T., J.L. and F.W. conceived the concept and designed the experiments. G.T. carried out the synthesis and performed materials characterization and electrochemical measurements. Y.F.Y., R.S.-Y. and J.L. carried out the in situ TEM experiments. R.C., T.Z., Y.Y. and J.L. discussed the data and provided the technical support. G.T., J.Q., J.R.L. and Y.S.Y. developed the theoretical structural modelling. G.T., J.L. and K.A. co-wrote the paper. All authors discussed the experiments and final manuscript.

\section{Additional information}

Supplementary Information accompanies this paper at http://www.nature.com/ naturecommunications

Competing financial interests: The authors declare no competing financial interests.

Reprints and permission information is available online at http://npg.nature.com/ reprintsandpermissions/

How to cite this article: Tan, G. et al. Freestanding three-dimensional core-shell nanoarrays for lithium-ion battery anodes. Nat. Commun. 7:11774 doi: $10.1038 /$ ncomms11774 (2016).

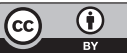

This work is licensed under a Creative Commons Attribution 4.0 International License. The images or other third party material in this article are included in the article's Creative Commons license, unless indicated otherwise in the credit line; if the material is not included under the Creative Commons license, users will need to obtain permission from the license holder to reproduce the material. To view a copy of this license, visit http://creativecommons.org/licenses/by/4.0/ 